\title{
Anatomy Education Re-imagined
}

Venkatesh $\mathrm{A}^{1}$

${ }^{1}$ University of Aberdeen, Scotland, United Kingdom

The SARS-CoV-2 (COVID-19) pandemic led to a seismic shift in learning and teaching. There was an abrupt halt to in-person teaching and a rapid pivot towards online solutions (1) including in the field of Anatomy education $(2,3)$ where teaching and learning previously usually involved human cadaveric laboratory sessions. With lab access halted, institutions deployed contingency measures (4) and used online Anatomy resources including 3D, virtual reality and videos to bridge the gap (5).

One year on, vaccines raise hopes of return to normalcy. But having successfully integrated innovative techniques into the anatomy educators' toolkit, we can reimagine how Anatomy education is delivered. Here we describe some teaching modalities we successfully used during the pandemic that we will embed into our future Anatomy teaching and review literature that underpins the pedagogic principles of these teaching techniques.

\section{Section 1: The Context}

\subsection{Anatomy education at Aberdeen}

At the University of Aberdeen Anatomy is taught to healthcare students (Medicine, Dentistry, Physicians' Associate) and some groups of BSc students. The majority of gross anatomy teaching is prosection-based. There are strict guidelines about use and upkeep of cadaveric materials in Scotland namely the
Anatomy Act 1984 (6), as modified by the Human Tissue Act (Scotland) 2006 (7). Hitherto an issue we have been cautious about was the capture, storage and use of cadaveric images. Even with appropriately consented cadavers, images were only captured and used for specific projects and publications, not for regular teaching and never uploaded online for teaching including to our password protected Virtual Learning Environments (VLE). Students undertake a lecture about the Anatomy Act and sign a Code of Conduct at the start of the academic year agreeing to abide by our regulations.

\subsection{Student learning preferences and learning $\underline{\text { materials }}$}

Anatomy is a visual subject and learning gross anatomy is best achieved by engaging with cadaveric specimens or models. It appeals to students with visual and kinaesthetic learning preferences. Additional learning activities such as lectures, interactive tutorials, workbooks, lab manuals or online resources supplement practical learning. In designing and using a wide range of teaching modalities our aim as educators is to engage students of different learning preferences. There are various theories about student learning preferences, here we refer to the VARK theory (8) which proposes that learners prefer one or more of Visual, Auditory, Read-Write or Kinaesthetic modalities. 


\section{Section 2: COVID adaptations to Anatomy teaching at Aberdeen}

At the start of the pandemic our immediate response was to put together online synchronous (live) lectures and tutorials or asynchronous lecture recordings. Later we began to modify and incorporate other teaching adaptations to improve student engagement and learning. Below are six such adaptations that we will continue after pandemic restrictions end.

\subsection{The electronic workbook:}

At Aberdeen, we provide Anatomy students with bespoke printed workbooks aligned to local learning outcomes. Workbooks offer a framework for students through questions and tasks that promote learner engagement with lab material. Hoadley and Galant (9) believe that workbooks function as curricular tools providing tasks "to help students master concepts".

Unable to run lab sessions, we produced electronic workbooks that embedded links to subscribed commercially available anatomy packages (dissection videos and 3D rotatable layered illustrations). This helped compensate for the loss of lab-based study and engaged students by asking them questions relating to the video or online resource. Students appreciated being guided through all subscribed resources (previously listed as recommended reading).

We intend to continue using such all-inclusive electronic workbooks but complement them with shorter physical worksheets for use in the lab.

\subsection{Live from the Lab:}

Demonstration as a method of teaching Anatomy is not new. Anatomy lecture theatres in the 1600s were often built like an amphitheatre to accommodate vast audiences (10). At Aberdeen demonstrations were used within the Anatomy labs to demonstrate tricky or intricate Anatomy using a visualiser (WolfVision VZ-C6 Ceiling Visualizer, $\mathrm{GmbH})$ that allowed magnification of intricate structures. A Live from the Lab session was such a demonstration beamed online from the lab to students in remote locations.

Ethical and safety considerations: We modified our Anatomy Code of Conduct to prohibit download of online cadaveric images onto personal devices. Our local IT team built a secure folder on our VLE to store recordings, accessible only by registered students signing in with university credentials. Conditions for viewing live events and their recordings were made explicit. Specifically, these sessions were to be viewed in privacy and not shared with friends or family. There are disciplinary processes if students break these conditions, but we found that explaining the importance of following the code (to avoid negative publicity which would undermine trust amongst public and thereby affect future cadaver donations) students demonstrate good citizenship and abide by it.

Student feedback suggests they found Live from the Lab a valuable resource and exposed some unexpected benefits; "access" to cadaveric teaching outside of class times and equity of experience for the class as the following comment suggests. 
"Live from the lab is better than anatomy last year because we all get to see the structures instead of crowding around [specimens] where people who were not at the front of the specimen...don't see anything" ( $2^{\text {nd }}$ year medical student)

DiLullo et al's (11) study found that live streaming dissection videos improved student satisfaction and self-perceived performance. Langfield et al (12) however warn that it promotes passive learning. To incorporate active learning, Live from the Lab tutors ask questions during the demonstration and students reply using the online platform's chat function. An observation we made is that through the chat function in online lessons students are more likely to engage in discussions than when face to face.

The success of these sessions including students' adherence to the Code of Conduct means that going forward we will continue to use such online demonstration especially in areas that students struggle.

\subsection{D rotatable cadaveric models:}

The technique of photogrammetry (13) has been used to reconstruct 3D rotatable cadaveric models. At Aberdeen a dedicated team have developed a bank of 3D cadaveric images (14) Compared to commercially available 3D resources they are authentic, made from departmental specimens and show more information including normal variations and pathology. Some models have step-by-step layered 'dissection' and labelling that familiarises students with spatial relationships. These resources appeal to visual and kinaesthetic learners. The use of our 3D models increased during the pandemic and adds value to the anatomists' toolkit.

\subsection{Interactive case-based discussions:}

Case based learning is thought to work by increasing motivation through group work, encouraging critical reflection (15) and also by integrating knowledge and practice (16). At Aberdeen we have used this format, getting students to work in small groups to solve clinical problems using relevant histology, histopathology and radiology. It was ideally suited to deliver online with minimal change. Students work in break-out groups and then feed back to the larger class discussion.

An additional benefit of this small-group format during COVID was that it allowed some student-to-student social interaction. There is growing concern that students' mental health has been impacted negatively during the pandemic partly because of their social isolation with very little face to face teaching. One study (17) found that $86 \%$ of participants thought that decreased social interactions led to build up of stress. We would like to believe that our case-based sessions alleviated this to a small degree.

\subsection{Online discussion forums:}

Discussion forums are an established tool in online courses and can promote higher level thinking (18). To create a community of learners, we asked students to use the discussion forum to discuss curricular queries with each other and faculty. While this was used with variable success, students 
themselves produced a live document for asynchronous discussion between students and tutors. We found it an efficient tool to get a feel for student learning and addressed their queries at a subsequent Live from the Lab or Q\&A session and we will continue using this going forwards.

\subsection{Online assessments:}

Our practical exam previously consisted of students undertaking a circuit of timed stations answering questions related to specimens, models or images which were then handmarked and totalled and collated manually. Most universities moved to online assessments during the pandemic. We moved our Anatomy exam to a secure online platform and physical specimens were replaced by images.

The advantage was the ability to look at exam statistics and question performance whereas previously the hand-marked format did not allow this. This is advantageous and postcovid we intend returning to in-person exams using specimens in the lab but with students answering on the online platform using a hand-held device such as a tablet.

\section{Conclusion}

The pandemic opened the doors to exciting new teaching techniques and incorporation of technology. Going forwards we are excitedly looking to return to our labs to teach and assess Anatomy but will hold on to these innovations thus improving our Anatomy teaching toolkit.
The techniques described here are low-cost and easy to set up. We hope that sharing our practice will encourage other departments world-wide to adopt what suits their circumstances and share their own good practice, thus building a global community of practice.

\section{Corresponding author}

Dr. Asha Venkatesh, Year 2 MBChB Lead, Athena SWAN lead (IEMDS), University of Aberdeen, UK.

\section{BY 4.0}

This is an Open Access article distributed under the terms of the Creative Commons Attribution 4.0 license (unless stated otherwise) which permits unrestricted use, distribution and reproduction in any medium, provided the original work is properly cited. Copyright is retained by the author(s).

\section{References}

1. Nordmann E, Horlin C, Hutchison J, Murray JA, Robson L, Seery M, MacKay J. 10 simple rules for supporting a temporary online pivot in higher education.

2. Evans DJ, Bay BH, Wilson TD, Smith CF, Lachman N, Pawlina W. Going virtual to support anatomy education: A STOPGAP in the midst of the Covid-19 pandemic. 
3. Pather N, Blyth P, Chapman JA, Dayal MR, Flack NA, Fogg QA, Green RA, Hulme AK, Johnson IP, Meyer AJ, Morley JW. Forced disruption of anatomy education in Australia and New Zealand: An acute response to the Covid-19 pandemic. Anatomical sciences education. 2020 May;13(3):284-300.

4. Brassett, C., Cosker, T., Davies, D.C., Dockery, P., Gillingwater, T.H., Lee, T.C., Milz, S., Parson, S.H., Quondamatteo, F. and Wilkinson, T., 2020. COVID-19 and anatomy: Stimulus and initial response. Journal of anatomy, 237(3), pp.393-403.

5. Iwanaga J, Loukas M, Dumont AS, Tubbs RS. A review of anatomy education during and after the COVID-19 pandemic: Revisiting traditional and modern methods to achieve future innovation. Clinical Anatomy. 2021 Jan;34(1):108-14.

6. Anatomy Act 1984.

legislation.gov.uk. http://www.legislation.g ov.uk/ukpga/1984/14/contents (accessed 24 March 2021)

7. Human Tissue (Scotland) Act 2006. legislation.gov.uk. http://www.legislation.g ov.uk/asp/2006/4/section/53 (accessed 24 March 2021)

8. Fleming N, Baume D. Learning Styles Again: VARKing up the right tree! Educational developments. 2006 Nov 4;7(4):4.

9. Hoadley U, Galant J. An Analysis of the Grade 3 Department of Basic Education
Workbooks as Curriculum Tools. South African Journal of Childhood Education. 2016;6(1):400.

10. Billing C. Modelling the anatomy theatre and the indoor hall theatre: dissection on the stages of early modern London. Early modern literary studies. 2004 Apr;13(3):17.

11. DiLullo C, Coughlin P, D'Angelo M, McGuinness M, Bandle J, Slotkin EM, Shainker SA, Wenger C, Berray SJ. Anatomy in a new curriculum: Facilitating the learning of gross anatomy using web access streaming dissection videos. Journal of visual communication in medicine. 2006 Jan 1;29(3):99-108.

12. Langfield T, Colthorpe K, Ainscough L. Online instructional anatomy videos: Student usage, self-efficacy, and performance in upper limb regional anatomy assessment. Anatomical sciences education. 2018 Sep;11(5):461-70.

13. Petriceks AH, Peterson AS, Angeles M, Brown WP, Srivastava S. Photogrammetry of human specimens: an innovation in anatomy education. Journal of medical education and curricular development. 2018 Sep;5:2382120518799356.

14. Struck R, Cordoni S, Aliotta S, PérezPachón L, Gröning F. Application of photogrammetry in biomedical science. Biomedical Visualisation. 2019:121-30.

15. Williams B. Case based learning - a review of the literature: is there scope for this educational paradigm in prehospital 